\title{
Large seismic events $(M>0)$ in the Lappberget orebody, Garpenberg, Sweden: blast or non-blast-related?
}

\author{
i Erguncu Güçlü Luleå University of Technology, Sweden \\ S Dineva Luleå University of Technology, and Luossavaara-Kiirunavaara Aktiebolag (LKAB), Sweden
}

S Mozaffari Luossavaara-Kiirunavaara Aktiebolag (LKAB), Sweden

A Nyström Boliden Mines, Sweden

\begin{abstract}
The definition of large magnitude events for mining-induced seismicity highly depends on the general pattern of seismicity in the underground mine. The seismic system in the underground Garpenberg Mine, located in Sweden, was installed in June 2012. In total, 40,000 events were recorded by the end of 2018 with the largest event of magnitude $M$ 2.3. The large seismic events in Garpenberg Mine are defined as the events with $M>0$ and very large events with $M>1$. This study is based on data from the Lappberget orebody from 2012 to the end of 2018.

A seismically active zone was defined in the Lappberget orebody on the northeast side with approximately $90 \%$ of the seismicity. The larger magnitude events occurred mostly in this zone too. The large events occurred at depth above 1,000 m, and the so-called very large seismic events, above $750 \mathrm{~m}$. The events in the upper levels, above $700 \mathrm{~m}$, are characterised by comparatively lower apparent stress than the events below.

It was found that $24 \%$ of the large seismic events were triggered by production blasts within 24 hours and $150 \mathrm{~m}$. Most of the blast-related large events occurred within two hours after blasting. Only a few large seismic events had intense aftershocks. The aftershock series lasts for around 10 hours and are within $150 \mathrm{~m}$ of the main shock. In case of more a complicated situation with blast relation and multiple large events, the aftershock series lasts more than 60 hours.

Based on the observations made here, some simple rules were defined for closing mine areas after large seismic events (so-called re-entry protocol for large seismic events). The reasonable restriction after the large seismic event would be three hours with a $150 \mathrm{~m}$ radius from the hypocentre of the large seismic event. The duration might be extended depending on the pattern of the aftershock sequence, especially for the large seismic events that occurred after blasting. In this case, the procedure of re-entry protocol for post-blast sequences must be followed. The obtained information about the relation between the large events and blasting can be used also for the re-entry protocol after blasting.
\end{abstract}

Keywords: mining-induced seismicity, large magnitude events, blasting, re-entry protocol

\section{Introduction}

Mining-induced seismicity deep underground mines has unique behaviour depending on the mining method and the geomechanical properties of the rock mass, even though some common patterns exist. The seismic events that can cause damage are one of the biggest concerns related to induced seismicity. Therefore, many researchers have focused on several aspects of these seismic events:

- Which events can cause significant damage (what is the minimum magnitude)?

- What is the leading cause of them? 
From a practical point of view, the results from such studies can provide information about the areas of increased seismic hazard and risk. Measures can be taken to avoid injures in case of increased risk by the temporary closure of mine areas and subsequent re-opening.

The definition of large seismic events depends on the seismicity pattern in the mine, and the magnitude scale which is used. For example, for Canadian mines which used Nutti magnitude ( $M_{N}$ ) (Disley 2014), large seismic events are with $M_{N}>1.5$ (Eneva 1998). In the USA, where Richter magnitude (M) is used, $M>2$ could generate damage and are considered large events (Friedel et al. 1997). Hudyma \& Potvin (2010) defined the seismic hazard in Australian mines as low for $M=0$, moderate for $M=1$, and high for $M=2$ on a Richter magnitude scale.

The magnitude scale used in Swedish mines was developed by the Institute of Mine Seismology (IMS) for South African mines (Riemer \& Durrheim 2012) based on Richter magnitude scale. Although Swedish mines also use the IMS magnitude scale, it is not calibrated for them. Events with magnitude roughly above 0 to 0.5 in Kiirunavaara Mine using this scale are considered capable of causing damage (Nordström et al. 2017). Analysis of data for damaging events from Garpenberg Mine showed even very small events with $\mathrm{M}$ down to -1.9 can cause minor damage. More significant damage was observed from events with $M>0$. That is why the events with magnitude $>0$ were defined as large in this study.

The occurrence of large seismic events depends on several factors, such as high stress, geological and geomechanical conditions, mining methods, and development and production blasting. The dynamic stress from the blast and the adaptation to the new stress condition after blasting could cause a large seismic event. Some seismic events follow the blast almost immediately, but some can follow in hours. The conditions of the rock mass could play a significant role in the new stress conditions and the intensity of the large seismic events. The pre-existing faults and dykes are probably the most important structures where large seismic events might occur (Hudyma \& Potvin 2010).

In this paper, the large seismic events $(M>0)$ and very large events $(M>1)$ in the Lappberget orebody were studied to define their location, dynamic source parameters in terms of magnitude classification, and relation to blasts. The first step was to identify the spatiotemporal distribution and dynamic source parameters ranges. Second, the relation of the large events to production blasting was studied using preselected criteria. The fore/aftershock series of the large seismic events were also investigated. The final aim was to define some rules for closing and re-opening of the mine area due to increased seismic risk after blasting and after larger seismic events.

\section{Garpenberg Mine}

Garpenberg Mine, the oldest mine site in Sweden, is more than 1,000 years old (Jansson 2011). It is one of the metalliferous mines in Sweden, producing approximately 2.5 tonnes of $\mathrm{Zn}-\mathrm{Pb}-\mathrm{Ag}-(\mathrm{Cu}-\mathrm{Au})$ ore per year. The current mining method is sublevel stoping. The mining operation is continuous at the various orebodies at various depths.

Problems related to the mining-induced seismicity started before the installation of the first geophone in the permanent system sensors in May 2012. The first recorded seismic event was on 22 June 2012, at the Kaspersbo orebody.

\subsection{Geology}

The mine site is located in the Bergslagen region (Jansson \& Allen 2011) in metasedimentary and predominantly felsic metavolcanic rocks (Jansson 2011). The complexity of the region came from several deformations, alteration, and metamorphism stages (Allen et al. 2003). The Garpenberg Mine site consists of several orebodies: Garpenberg, Dammsjön, Lappberget, Garpenberg Norra, Kaspersbo and Gransjön. They lie in limestone syncline (Figure 1a). The Lappberget orebody has the largest sulphide deposit on the mining site. The available information about the structure around Lappberget presents a complex structure. Although the caprock is homogeneous, the geological structures in the footwall and hanging wall are highly 
complicated. The main alteration in the hanging wall is silification and structures in the footwall and around the orebody are highly complex (Ahmadi et al. 2013) (Figure 1b).

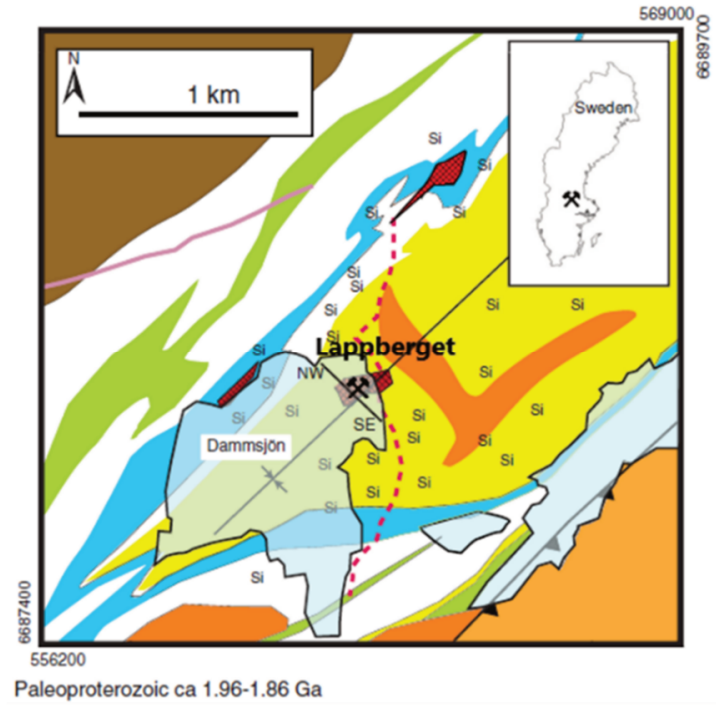

(a)

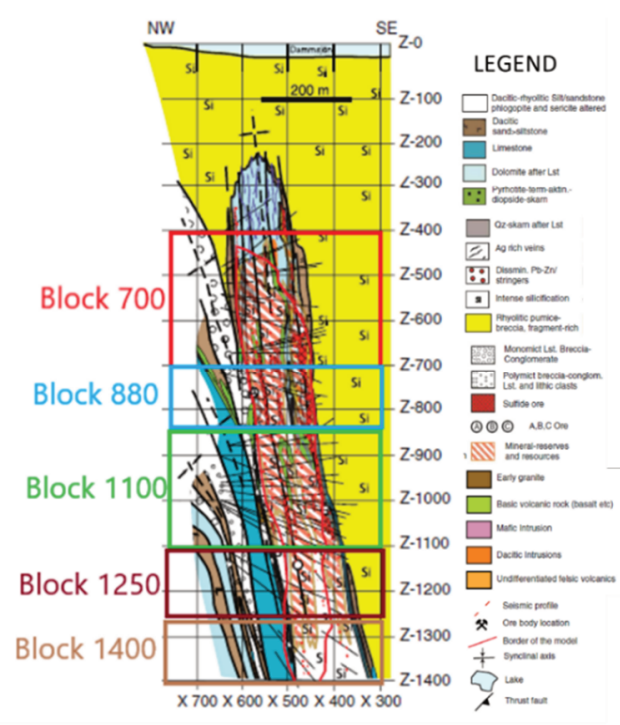

(b)

Figure 1 (a) Geology of the Garpenberg Mine, location of Lappberget orebody marked with mining symbol; (b) Vertical geological model of the Lappberget orebody with mine blocks (modified after Ahmedi et al. 2013)

\subsection{Mining method}

Sublevel stoping is a high productivity, lower cost mining method, mostly used at underground metalliferous mines (Villaescusa 2014). The regular orebody is divided into blocks and then stopes. In the Garpenberg Mine, sublevel stoping was chosen as the mining method. The Lappberget orebody is divided into five blocks (Figure 1b). The operation is ongoing in parallel in all blocks.

Figure 2 presents the operated stopes in Block 1250. The primary and secondary stopes are presented with yellow and blue piles, respectively. The operation starts at the bottom of the blocks and moves upwards. The stopes are taken in sequence of primary and secondary stopes. Secondary stopes are mined out when adjacent primaries are taken and backfilled with paste. The sequence starts from the middle of the block and creates a V-form shape upwards.

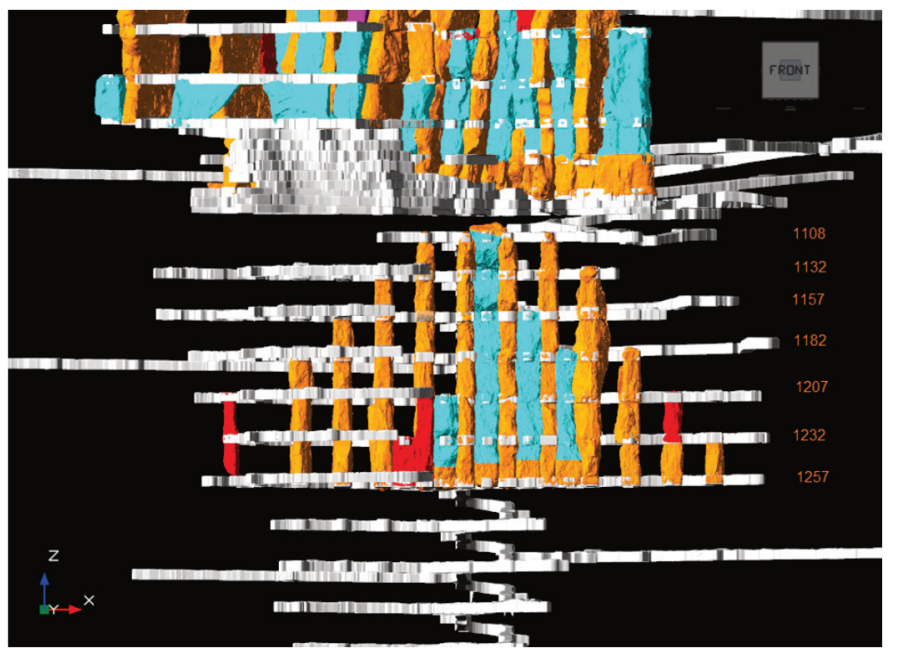

Figure 2 Example of the shape of selected mining method in the Garpenberg Mine in Block 1250 at Lappberget orebody. The yellow piles are primary stopes, and the blue piles are secondary stopes 
The stopes are also divided into two or three rooms. The number of the rooms in the stope is determined by the total length of the stope and geometry of the orebody. The first blasted room is the smallest one. Then the size of the rooms generally increase. However, the charge used to blast the rooms is not less than $1,000 \mathrm{~kg}$ of explosives. The amount of explosives could be up to $15,000 \mathrm{~kg}$. The average amount of explosives is around $6,600 \mathrm{~kg}$ per production blast.

\section{Seismicity in Garpenberg Mine}

The permanent seismic system has been installed in June 2012 and upgraded several times. The number of sensors increased to 27 by the end of 2018. Almost 40,000 events have been recorded by the end of 2018 in the whole mine, with 193 large events $(M>0)$. The spatial distribution of the events is given in Figure $3 a$. The largest event in the catalogue is M 2.3 in Karspersbo, on 15 November 2015 at 3:14 am. The smallest recorded event is M -5.2 in the Kaspersbo orebody. Almost all of the seismic events occurred around the orebodies. The sensor coverage is the best for the Kaspersbo orebody and that is why the smallest magnitude events are recorded there.

Around 11,400 events were recorded in and around the Lappberget orebody by the end of 2018 with 84 large and eight very large events. Figure $3 \mathrm{~b}$ shows the density of the events in and around the orebody. The sensors in the seismic system are located down to Block 1100 with the deepest sensor one at depth $-1,087 \mathrm{~m}$. Therefore, there is no sensor coverage in the lower blocks (Block 1250-1400). Another small seismic network was installed by INERIS in Block 1250 in 2014 as part of a research project.

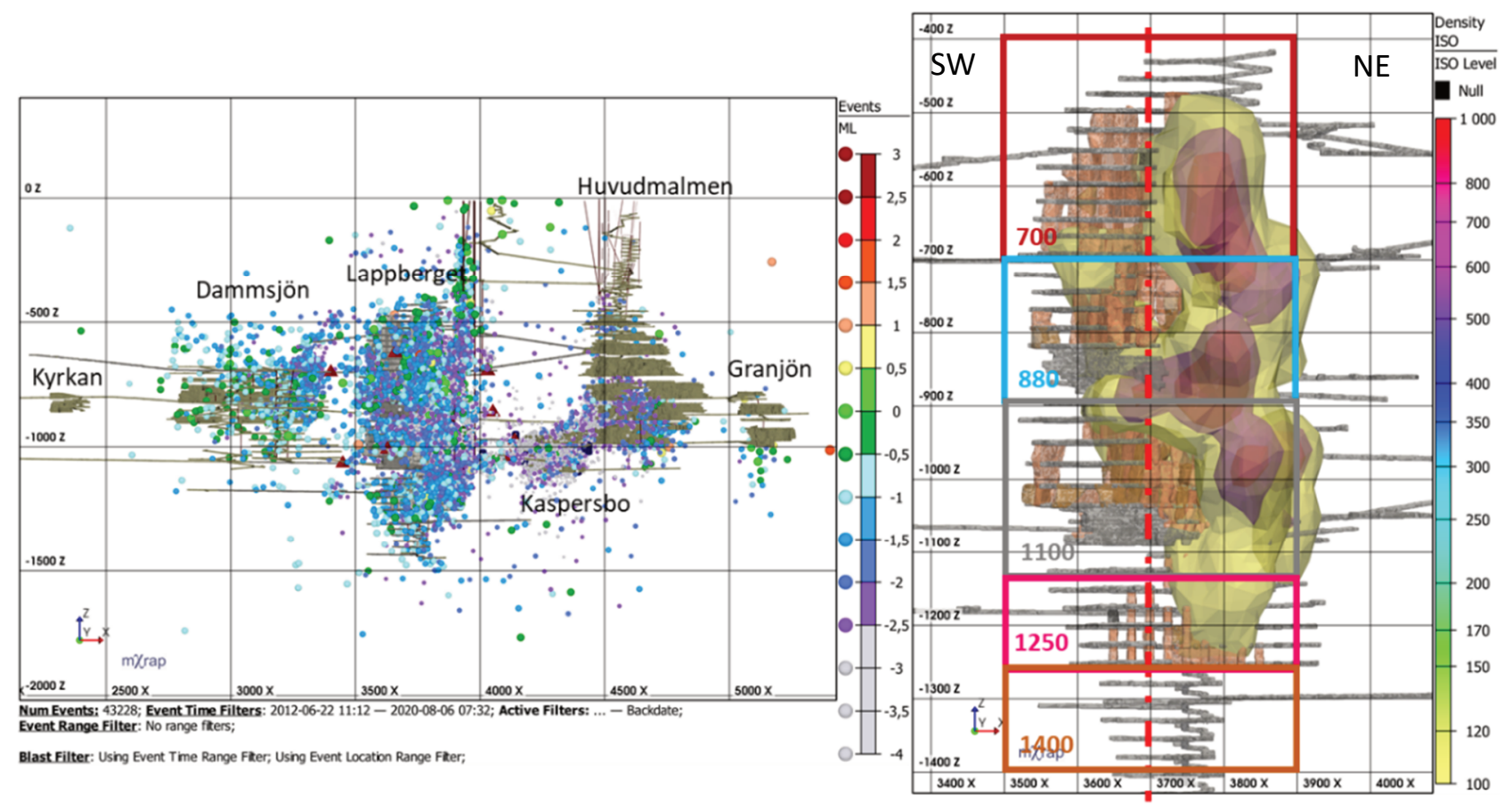

(a)

(b)

Figure 3 (a) Seismic events in Garpenberg Mine from June 2012 to December 2018; (b) Density distribution of the events in Lappberget orebody. The colour and size of the seismic events represents the local magnitude of the events. The red triangles and blue squares are the locations of triaxial and uniaxial sensors. The red dashed line in (b) divides roughly the seismically more active and less active zone. The mining blocks are outlined in (b) 
For this study, spatial filtering of the seismic events in the Lappberget orebody was done to exclude the orepass events in the northeast side of the orebody. This study covers only the upper three blocks in Lappberget because of two reasons (Blocks 700, 880, and 1100) for the period 2012-2018. The seismicity in Block 1250 is studied by INERIS. The mining operation in Block 1400 will be started in 2021.

Figures $3 a$ and $b$ show clearly that the northeast side of the orebody (right side on the figures) experienced more seismic events than the southwest side. The sensor layout does not play a role in this result. The orebody could be divided roughly into two vertical zones in terms of seismicity (divided by the red dashed line in Figure $3 \mathrm{~b}$ ). We call the northeast zone the seismically active zone. Almost $90 \%$ of the seismic events occur in this zone. The geological surveys (e.g. borehole data) show that the strength of rock mass in the northeast part of the orebody and above $-700 \mathrm{~m}$ is the strongest. It may explain the seismogenic zone in the northeast side.

The frequency-magnitude plot (Gutenberg-Richter plot) of the Lappberget orebody from 2012 to 2018 (Figure 4) shows a magnitude of completeness of -1.5 . The estimated b-value of the plot is $0.86 \pm 0.02$. The slope of $b$-value in Figure 4 has a good agreement for the events up to magnitude 0 . Then the degree of fit decreases (the tail is truncated).

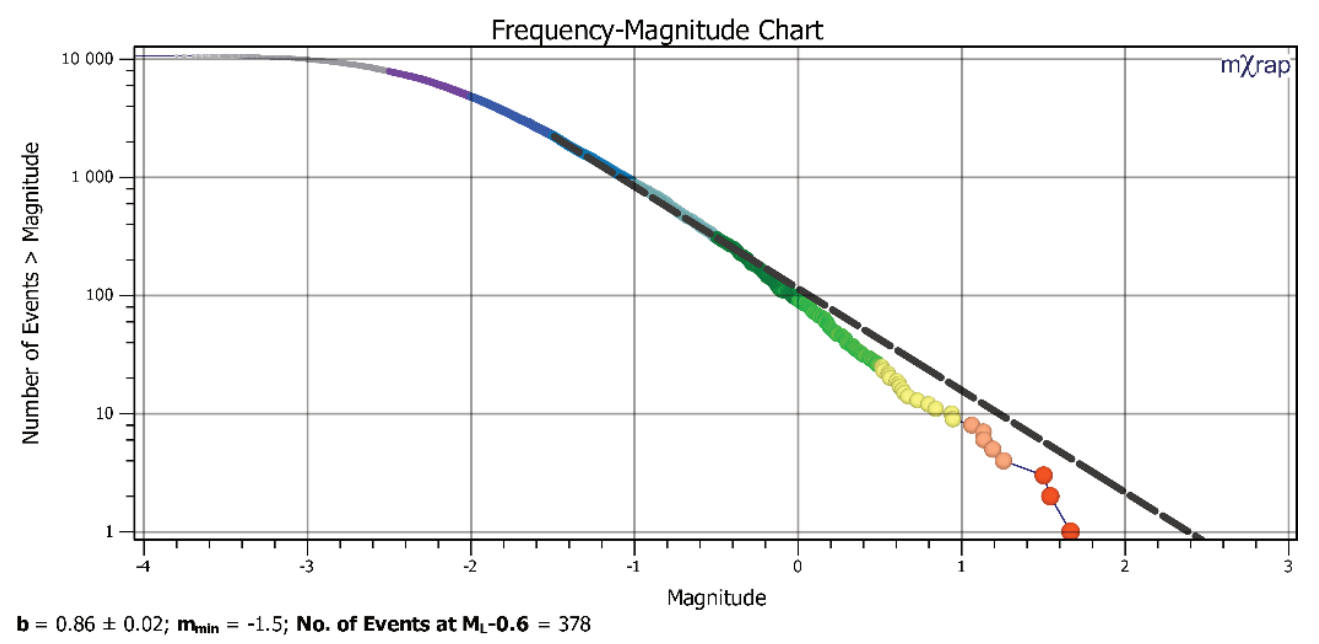

Figure 4 Frequency-magnitude plot of seismic events in the Garpenberg Mine from June 2012 to December 2018. The size and the colour of the spheres correspond to the local magnitude

The number of recorded seismic events in different mine blocks per year is given in Table 1 with the magnitude range, magnitude of completeness (Mc), b-value, and the number of large events. The highest number of seismic events has been recorded in 2013 and 2014. This is a result of the lower trigger level and higher sensitivity of the system at this time. The influence of the seismic system configuration is also seen in the magnitude of completeness. The trigger level of the system increased in May 2014, and the minimum magnitude and magnitude of completeness increased approximately by 0.5 to 1.0 magnitude units, respectively. As a result, the number of the seismic events decreased. The number of events per block varies, but in most years it is largest in Block 1100. These are predominantly smaller events compared to the other two blocks. The b-values for this block for all years except 2013 are the highest. 
Table 1 Number of seismic events, magnitude range, b-value and number of large seismic events for different blocks in the Lappberget orebody by years

\begin{tabular}{|c|c|c|c|c|c|c|c|}
\hline & $\begin{array}{l}2012 \\
\text { (7 months) }\end{array}$ & 2013 & 2014 & 2015 & 2016 & 2017 & 2018 \\
\hline \multicolumn{8}{|c|}{ Number of seismic events } \\
\hline Block 700 & 62 & 501 & 947 & 439 & 242 & 161 & 319 \\
\hline Block 880 & 193 & 1,017 & 587 & 257 & 231 & 124 & 236 \\
\hline Block 1100 & 1,308 & 1,617 & 571 & 162 & 293 & 531 & 570 \\
\hline Total & 1,866 & 3,135 & 2,105 & 858 & 766 & 816 & 1,125 \\
\hline \multicolumn{8}{|c|}{ Magnitude range } \\
\hline Block 700 & -3.0 to 1.5 & -3.0 to 0.7 & -3.1 to 1.7 & -2.7 to 0.6 & -2.2 to 1.3 & -2.0 to 0.3 & -2.3 to 1.5 \\
\hline Block 880 & -3.3 to -0.15 & -3.6 to 0.6 & -3.5 to 0.8 & -2.8 to 1.2 & -2.4 to 0.4 & -2.3 to 0.1 & -2.3 to 0.6 \\
\hline Block 1100 & -4.2 to 0.5 & -3.8 to 1.1 & -3.6 to -0.3 & -3.0 to -0.2 & -2.6 to 0 & -2.6 to 0.2 & -3.1 to 0.1 \\
\hline Total & -4.2 to 1.5 & -3.8 to 1.1 & -3.6 to 1.7 & -3.0 to 1.2 & -2.6 to 1.3 & -2.6 to 0.3 & -3.1 to 1.5 \\
\hline Mc & & -2.3 & -2.4 & -1.5 & -1.5 & -1.1 & -1.5 \\
\hline \multicolumn{8}{|c|}{ b-value } \\
\hline Block 700 & $0.64 \pm 0.04$ & $0.81 \pm 0.04$ & $0.66 \pm 0.03$ & $0.93 \pm 0.07$ & $0.93 \pm 0.09$ & $0.99 \pm 0.1$ & $0.9 \pm 0.06$ \\
\hline Block 880 & $0.71 \pm 0.06$ & $0.81 \pm 0.04$ & $0.63 \pm 0.03$ & $0.78 \pm 0.06$ & $0.95 \pm 0.09$ & $0.95 \pm 0.1$ & $0.92 \pm 0.09$ \\
\hline Block 1100 & $0.73 \pm 0.03$ & $0.72 \pm 0.03$ & $0.74 \pm 0.04$ & $1.2 \pm 0.12$ & $0.98 \pm 0.08$ & $1.14 \pm 0.06$ & $1.32 \pm 0.12$ \\
\hline Overall & $0.66 \pm 0.02$ & $0.79 \pm 0.02$ & $0.64 \pm 0.02$ & $0.88 \pm 0.05$ & $0.93 \pm 0.05$ & $1.14 \pm 0.1$ & $0.99 \pm 0.05$ \\
\hline \multicolumn{8}{|c|}{ Large seismic events } \\
\hline Large events & 13 & 10 & 22 & 12 & 9 & 5 & 12 \\
\hline $\begin{array}{l}\text { Very large } \\
\text { events }\end{array}$ & 2 & 1 & 2 & 1 & 1 & 0 & 1 \\
\hline
\end{tabular}

Figure 5 shows the magnitude-time plot of the seismic events, and the cumulative number of events with $M>-1$. The seismicity rate in the studied three blocks in the Lappberget orebody from 2012-2018 was almost stable after May 2014 when the sensitivity changed. The number of large events was the largest in 2014 (22 events) and the smallest in 2017 (five events). The fluctuations before May 2014 might be due to incomplete recording of very small events (with magnitude below the completeness magnitude). The grey events in Figure 5 clearly show the difference between the magnitude of completeness before and after May 2014. The number of very large events is up to two per year. There is a good negative correlation between the overall $b$-value and the number of large events per year - a smaller b-value corresponds to a higher number of large events per year (Table 1 ). 


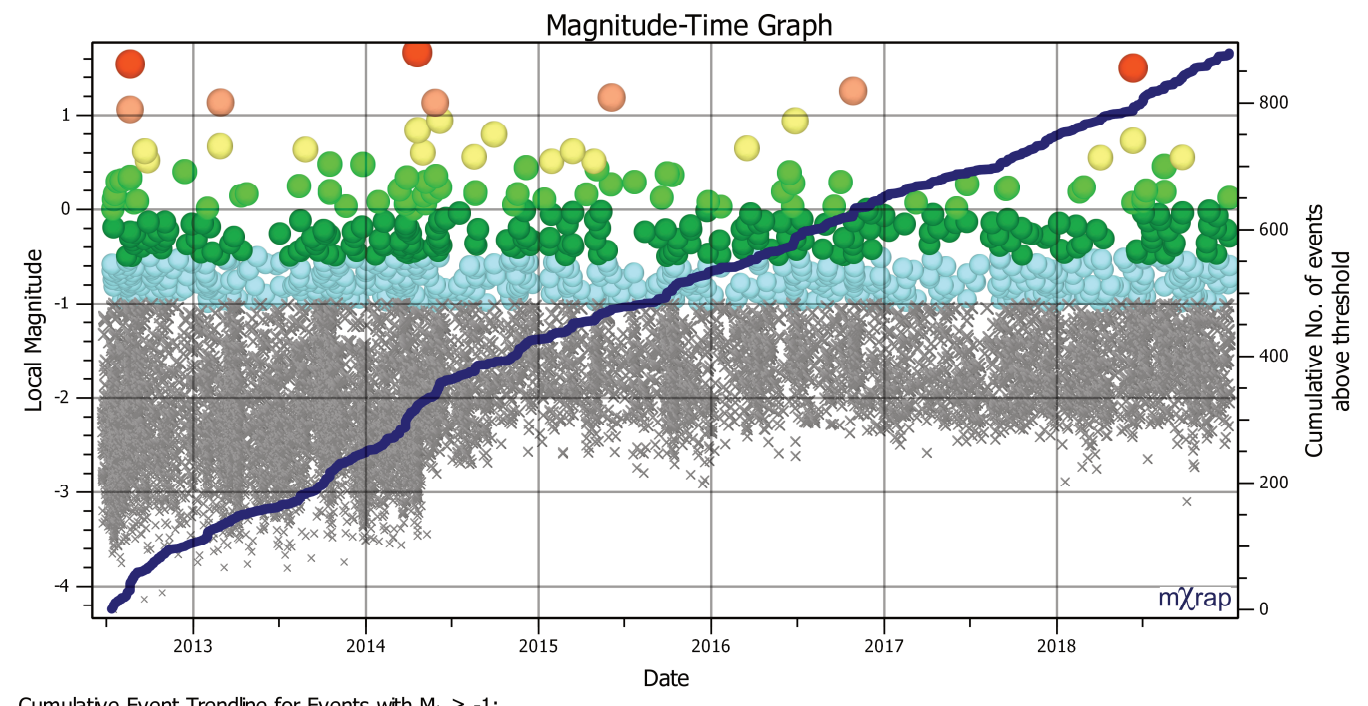

Cumulative Event Trendline for Events with $M L \geq-1$;

Figure 5 Magnitude-time distribution of the seismic event in three upper blocks in the Lappberget orebody from 2012 to 2018

\section{$4 \quad$ Large magnitude event characteristics}

\subsection{Locations and magnitude}

Hypocentre locations in Garpenberg Mine are routinely calculated by IMS using a procedure described in Nordström et al. (2017). The accuracy of the locations depends on the sensor coverage and especially the azimuthal coverage (Erguncu Güçlü 2016). The average accuracy is in the order of $31 \mathrm{~m}$.

The magnitude $M$ is calculated using the seismic energy and the seismic moment as follows:

$$
M=0.344+\log \left(E_{s}\right)+0.516 \log \left(M_{o}\right)-6.594
$$

where:

$$
\begin{aligned}
& E_{S}[J]=\text { the seismic energy. } \\
& M_{0}[N . m]=\text { the seismic moment. }
\end{aligned}
$$

In total, 92 large seismic events ( $M>0$ ) occurred from 2012 to 2018 in the Lappberget orebody. These events were not equally distributed in all blocks. The largest number of events occurred in the uppermost Blocks 700 and 880 (respectively 49 and 24) and the smallest in Block 1100 (18). Only one large seismic event was found outside of the blocks under investigation. The spatial distribution of large events on the $\mathrm{XZ}$ and $\mathrm{YZ}$ planes is shown in Figure 6 together with the origin time on the $\mathrm{YZ}$ plane. A significant number of large seismic events $(84,91 \%)$ occurred in the seismically active zone (the right side of Figure $6 a)$.

The large seismic events in the Lappberget orebody migrated within Blocks 700 and 880 as the first events were in the hanging wall (up) and then they migrated down towards the northeast side (Figure 6c). After 2016, they occurred in the footwall side, relatively far from the orebody. There is no clear migration pattern in the lower Block 1100. The migration pattern in each block is influenced most probably by the mining sequence, accumulated stresses, and the geological and geomechanical properties. Due to the sequence of the mining operation (upwards in each block) and the pre-mined level (cut-and-fill) between -900 and $-800 \mathrm{~m}$, more stresses accumulate in the sill pillar between the blocks.

Six out of eight very large seismic events occurred in Block 700 , and one of them just below $-700 \mathrm{~m}$. The largest magnitude event in Block 1100 was relatively far from the orebody ( $150 \mathrm{~m}$ ). 


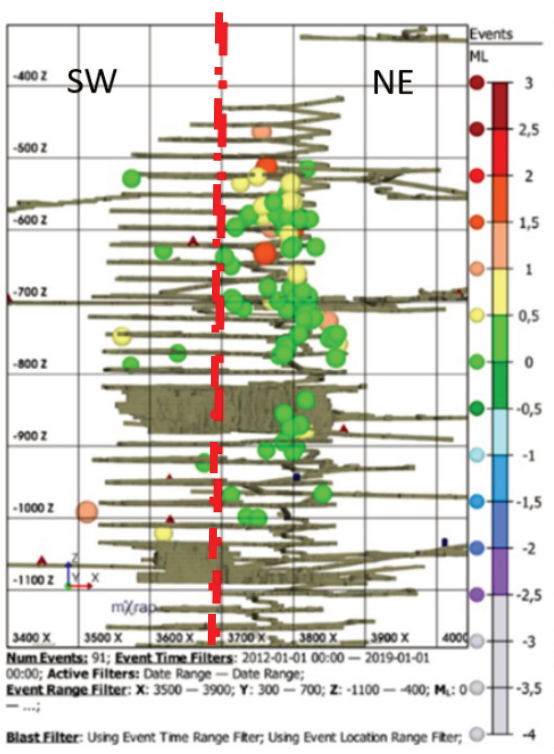

(a)

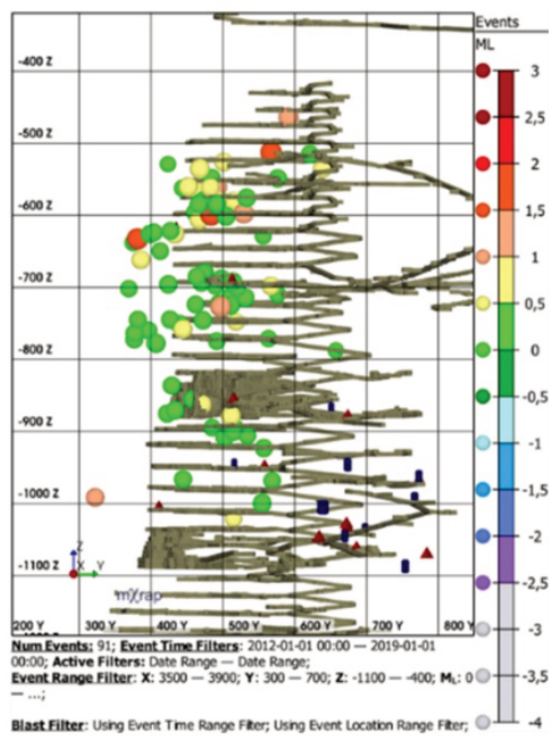

(b)

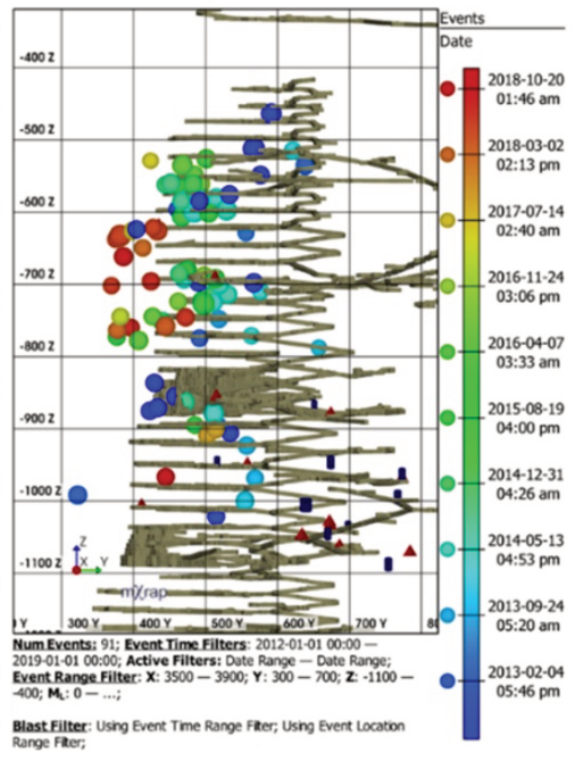

(c)

Figure 6 Spatial distribution of the large seismic events $M>0$ on (a) XZ plane; (b) YZ plane; (c) Temporal distribution on $\mathrm{YZ}$ plane. The size of the spheres corresponds to the local magnitude of the events

Figure 7 shows the location of the large seismic events in four magnitude ranges. Sixty-six events with $0<M<0.5$ were located almost all in the northeast side of the orebody (Figure 7a). Seventeen events with $0.5<M<1.0$ (Figure $7 \mathrm{~b}$ ) and the very large events $M>1$ except one event are also on the northeast side, mostly in Block 700. The geology of the upper part of Lappberget shows significant changes in the rock strength. At the northeast side of the orebody, the rock mass contains. This contrast even can be identified even by the wear of drill bits during production drilling.

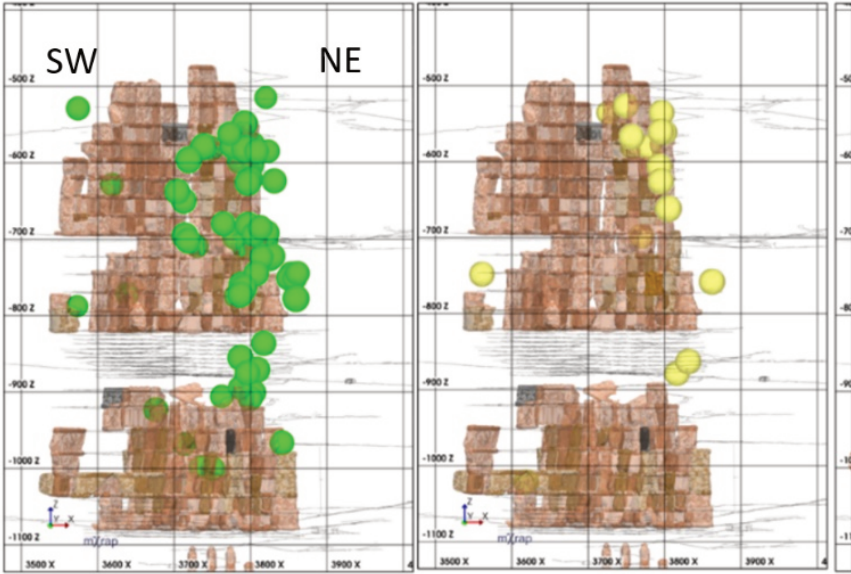

(a) (b)

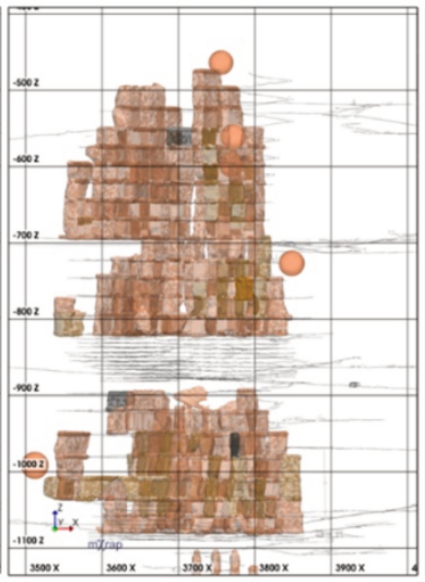

(c)

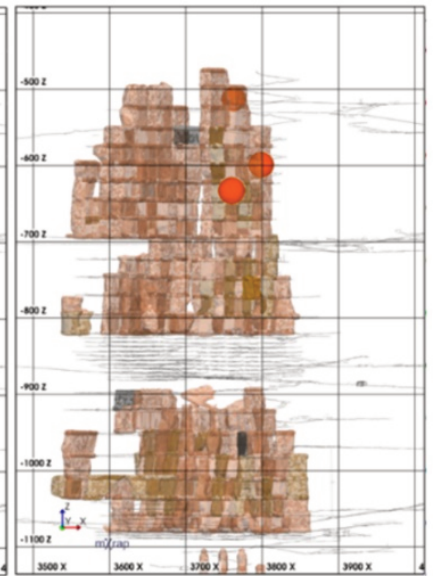

(d)

Figure 7 The location of the seismic events. (a) $0 \leq M<0.5$; (b) $0.5 \leq M<1$; (c) $1 \leq M<1.5$; (d) $M \geq 1.5$

\subsection{Dynamic source parameters}

Dynamic source parameters (seismic moment, potency, seismic energy, source radius, apparent stress, static stress drop, $E_{S} / E_{p}$ ratio, and apparent volume) are also routinely calculated by IMS following the procedure described in Mendecki (1997).

Table 2 shows the range of each parameter for both types of events-large and very large. The seismic moment varied from $3.0 \times 10^{9}$ to $8.3 \times 10^{11} \mathrm{~N}$.m, seismic energy from $5.0 \times 10^{3}$ to $1.6 \times 10^{6} \mathrm{~J}$ and source radius 
of from 5 to $160 \mathrm{~m}$ (Brune 1970). It is interesting to note that the very large seismic events had higher seismic moment and energy but lower overall apparent stress and static stress drop.

The estimated source mechanism using the $E_{s} / E_{p}$ ratio (Morkel et al. 2019) showed that 70 out of 83 large events and seven out of eight very large events had a non-shear source mechanism using $E_{s} / E_{p}=10$ as a boundary between non-shear and shear events.

Table 2 Range and average dynamic source parameters of the two groups of the large magnitude events

\begin{tabular}{|c|c|c|c|c|c|c|c|c|c|}
\hline & & 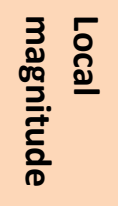 & 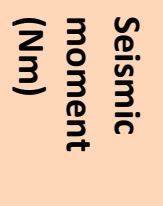 & 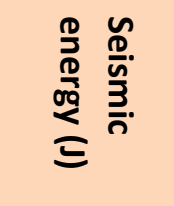 & 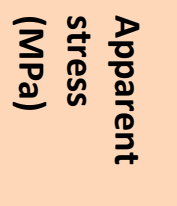 & 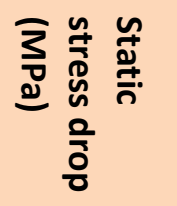 & 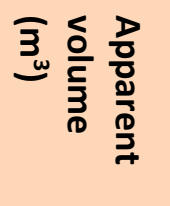 & 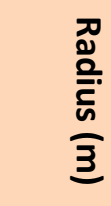 & $\underbrace{m}_{0}$ \\
\hline \multirow{2}{*}{$M>1$} & Min. & 1.1 & $1.00 \mathrm{E}+11$ & $1.50 \mathrm{E}+05$ & $2.10 \mathrm{E}-02$ & 7.50E-02 & $1.30 E+05$ & 28.9 & 1.7 \\
\hline & Max. & 1.7 & $8.30 E+11$ & $1.60 \mathrm{E}+06$ & $3.90 \mathrm{E}-01$ & $8.50 \mathrm{E}-01$ & $1.80 \mathrm{E}+07$ & 162.9 & 10.4 \\
\hline \multirow{2}{*}{$0<M<1$} & Min. & 0 & $3.00 E+09$ & $5.80 \mathrm{E}+03$ & $7.50 \mathrm{E}-03$ & 8.70E-03 & $1.20 \mathrm{E}+03$ & 5.2 & 0.5 \\
\hline & Max. & 1 & $1.70 E+11$ & $4.20 E+05$ & $1.30 \mathrm{E}+00$ & $5.20 \mathrm{E}+00$ & $5.00 E+06$ & 127.8 & 30.8 \\
\hline
\end{tabular}

Figures 8 and 9 show the locations of the non-shear and shear large events within 0.5 magnitude intervals. The non-shear events with magnitude 0 to 1 occurred in all three block with variable apparent stress and with some trend of increase with depth (Figures $8 a$ and b). The very large non-shear events are only in Block 700 (six out of eight) and have intermediate values of the apparent stress (Figures $8 \mathrm{c}$ and d). The shear events (Figure 9) occurred only in Blocks 880 and 1100 and have large apparent stress. Overall, the apparent stress does not correlate with the magnitude.

It has to be noted that a lot of large seismic events (both non-shear and shear) occurred in the sill pillar between Blocks 880 and 1100 . They have predominantly large apparent stress. It is expected that stress accumulated in the sill pillar is due to the mining operation. An unusual very large event occurred in Block 1100, quite far from the orebody (Figure 8c).

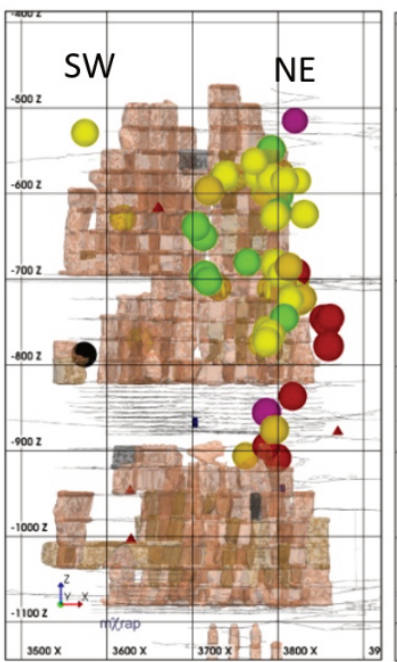

(a)

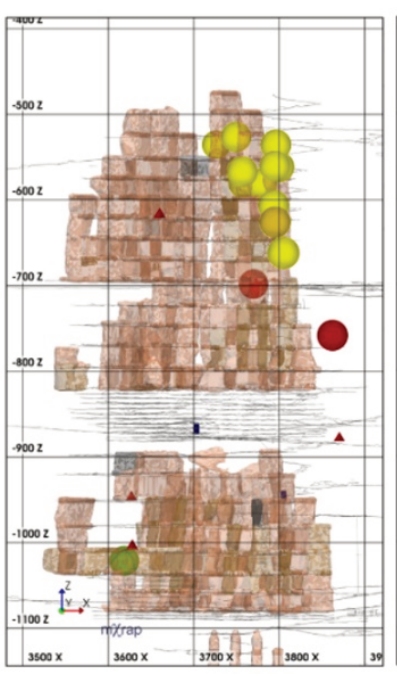

(b)

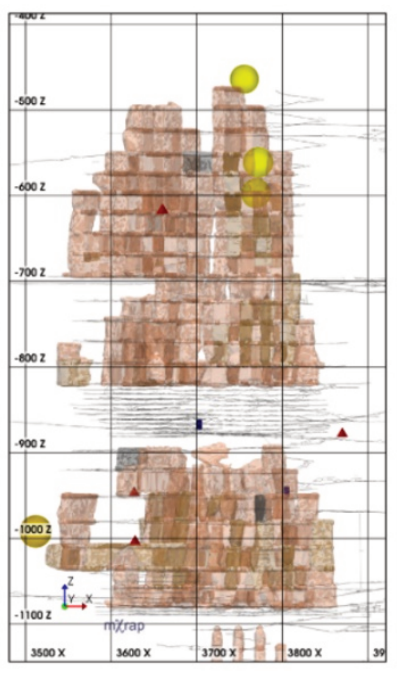

(c)

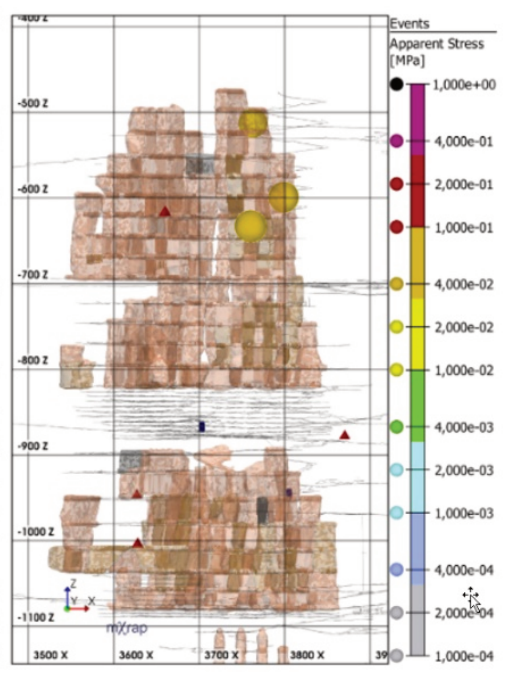

(d)

Figure 8 The apparent stress of the non-shear mechanism. (a) $0 \leq M<0.5$; (b) $0.5 \leq M<1$; (c) $1 \leq M<1.5$; (d) $M \geq 1.5$

The apparent volume was also found to be not correlated with the magnitude. The influence of the geological conditions and structures, as well as the stress conditions might give an explanation for the spatial patterns of the source parameters. 


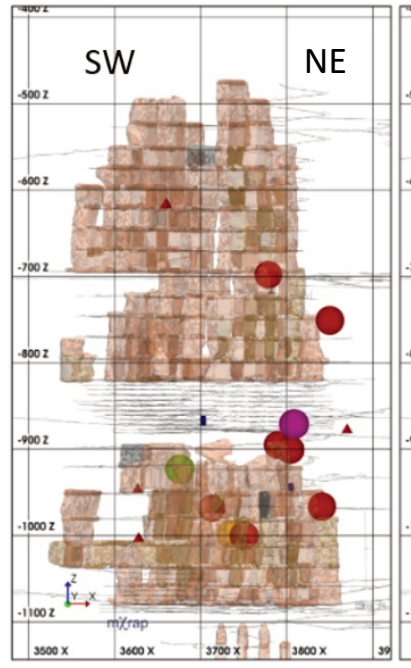

(a)

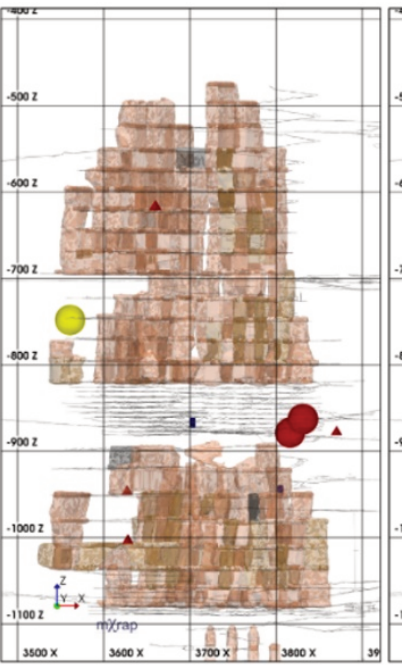

(b)

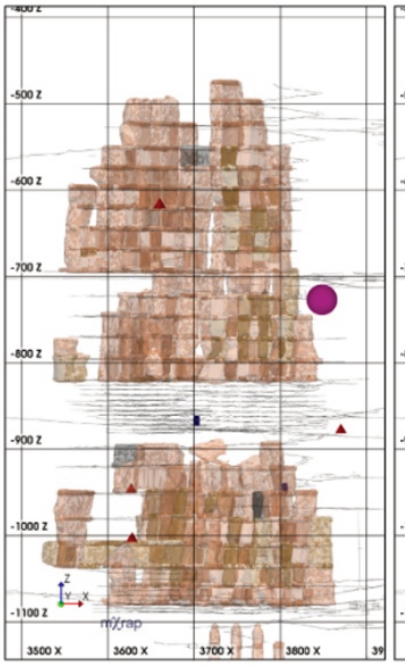

(c)

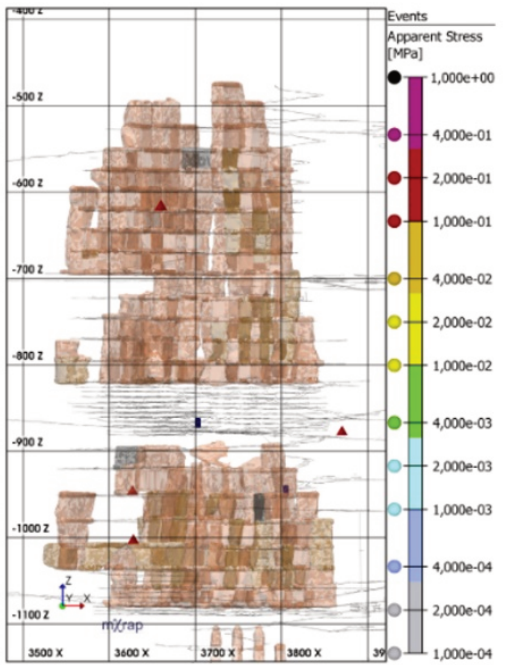

(d)

Figure 9 Apparent stress of the seismic events with shear mechanism. (a) $0 \leq M<0.5$; (b) $0.5 \leq M<1$; (c) $1 \leq M<1.5$; (d) $M \geq 1.5$

\section{$5 \quad$ Blast relation of large magnitude events}

A diurnal chart of the seismic events in the studied period for the Lappberget orebody indicated a correlation between seismic events and blasting (Figure 10). It shows that the rate of seismic activity (grey bars) dramatically increases after 4:00 pm as well as after 4:00 am, which are the regular blasting times for the mine. The number of seismic events with $M>0$ also increases dramatically at the same time.

All large events were investigated individually to determine if they were closely related in time and space and possibly triggered by blasting or not. The criteria were distance to the blast less than $250 \mathrm{~m}$ and time interval less than two days after the blast. These criteria were developed empirically by studying the post-blast seismicity (ongoing study). Then the large seismic events were classified based on these criteria as blast-related or non-blast-related.

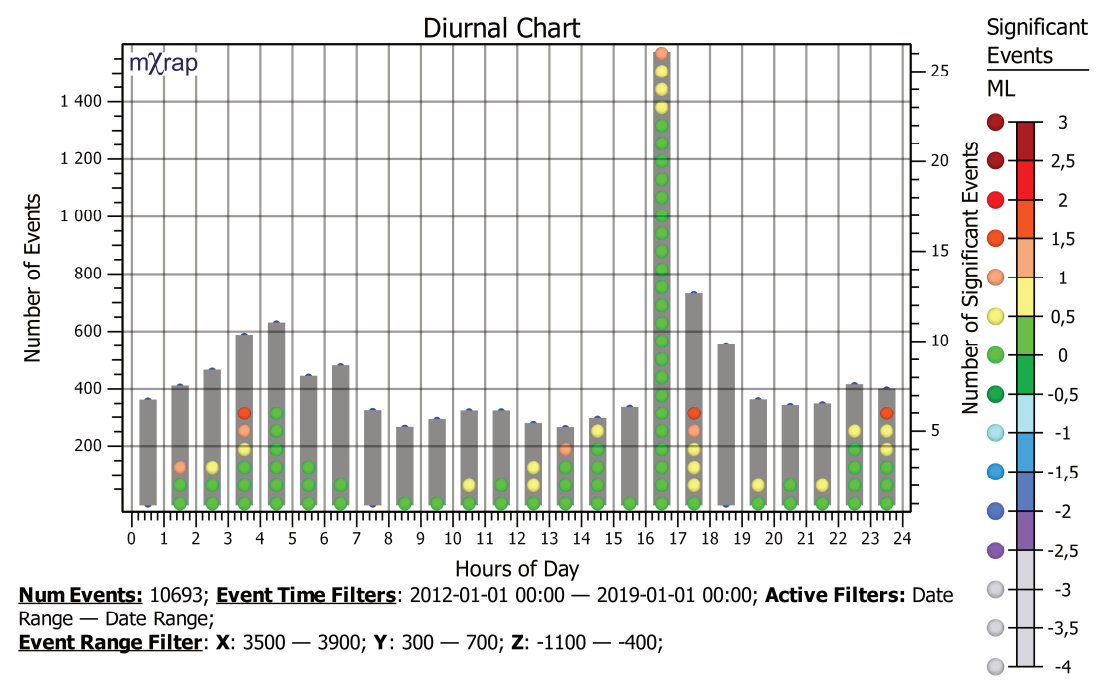

Figure 10 Diurnal chart of the seismic events in the Lappberget orebody from June 2012 to December 2018. The grey bars represent the number of events per hour. The colour spheres represent the seismic events with $M>0$

Due to the lack of information in the blast catalogue before 2013, the confirmation of blast relations between large events in 2012 (15 events) was not complete. The origin time of the blasted stopes in 2012, in a list 
provided by Boliden, matched only two of the events. They occurred before 5:00 pm. To avoid incorrect classification, all large events in 2012 were marked as unknown blast-triggered events. Correlation with blasting was done on large events after 2013 (67 events).

The confirmation of the blast triggering of the large seismic events was done in a relatively simple way. The blast catalogue was searched for blasts up to two days before the large seismic events within $250 \mathrm{~m}$ distance. If no blasts were found, the event was defined as non-blast-related.

\subsection{Non-blast-related large magnitude events}

It was confirmed that 54 large events (59.3\%) were not related to blasts. These events are called non-blast-related large seismic events. Fifteen large events in 2012 (16.4\%) were unknown. The spatial distribution of them is shown in Figure 11a. The non-blast-related and unknown events could occur at any time of the day, and their magnitude ranges between 0 and 1.6 .

\subsection{Blast-related large magnitude events}

It was found that $22(24.1 \%)$ events were related to a blast. Five of them were very large events and 17 were large events (Figure 11b). More than half of these events (68\%) were between 4:00 pm and 6:00 pm. Their magnitude range is 0 to 1.7. They occurred at any time after blasting but generally after 0.16 to 10 hours, on average $<3$ hours. Figure 12 shows the change of occurrence of any large events for less than 30 mins, two hours, 10 hours, and 24 hours. The change of occurrence of a large event after two hours till the next day drops to $32 \%$. The most critical period for occurring large events after blasting is the first two hours.

There is no clear spatial differentiation between the blast-related and non-blast-related events. They occurred almost at the same locations (Figure 11). Blast parameters (primary/secondary stopes or tonnage of explosive $(1,000$ to $15,000 \mathrm{~kg})$ ) did not play a role in either occurrence of large seismic events or the magnitude. However, the sequence also had some effect on the stress redistribution. Therefore, the blast-related large seismic events generally occurred close to the edge of the mining front, beside the primary stope. The primary stope at the edge of the orebody moves the stress front of the mining block and therefore the induced seismicity appears stronger in the more uninfluenced and competent rock mass.

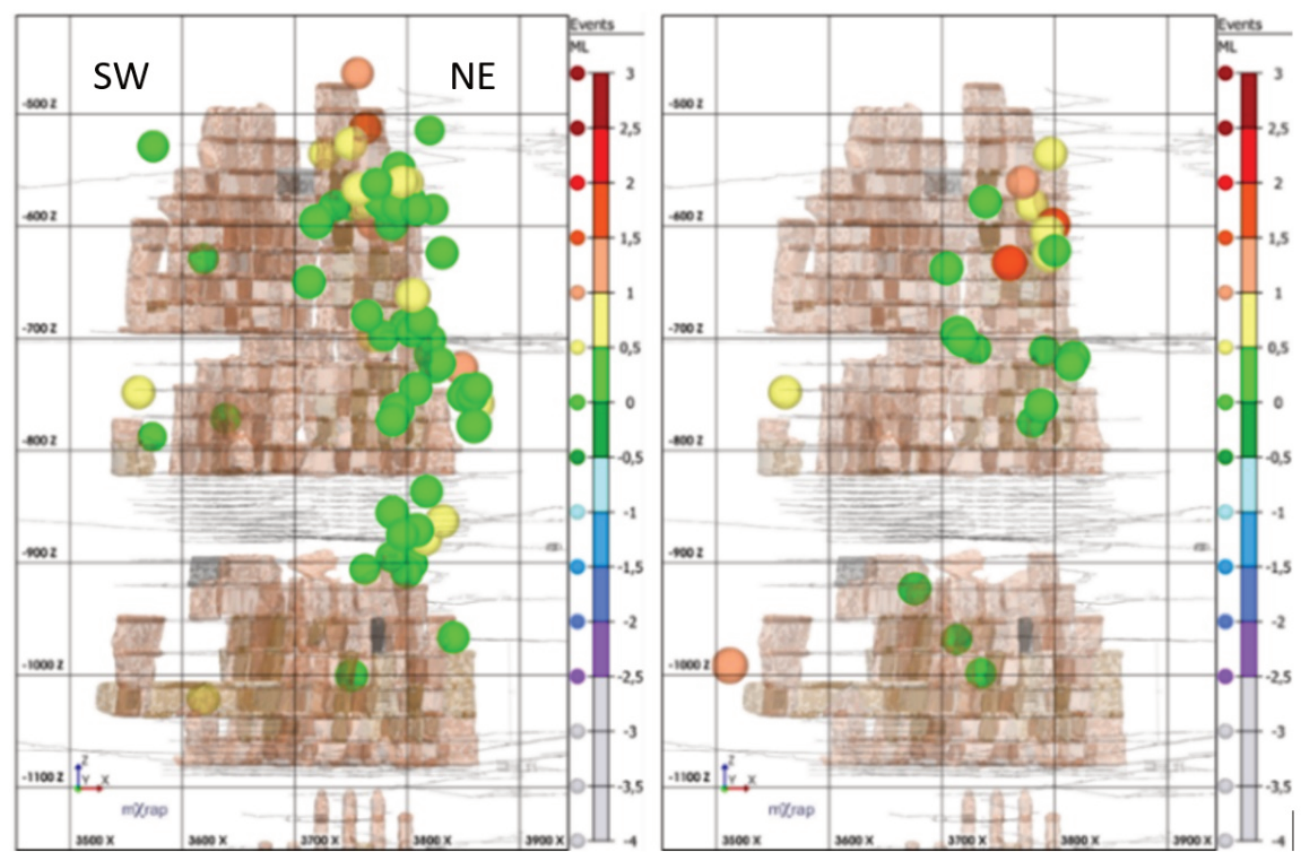

Figure 11 The spatial distribution of (a) Non-blast-related and unknown events; (b) Blast-related events from 2012-2018 
More than half of the blast-related events (68\%) occurred up to two hours after the blast (Figure 12). A small amount of large events (18\%) occurred between two and 10 hours after the blast, and another $13 \%$ between 10 and 24 hours. The most critical period for occurring large events after blasting is the first two hours.

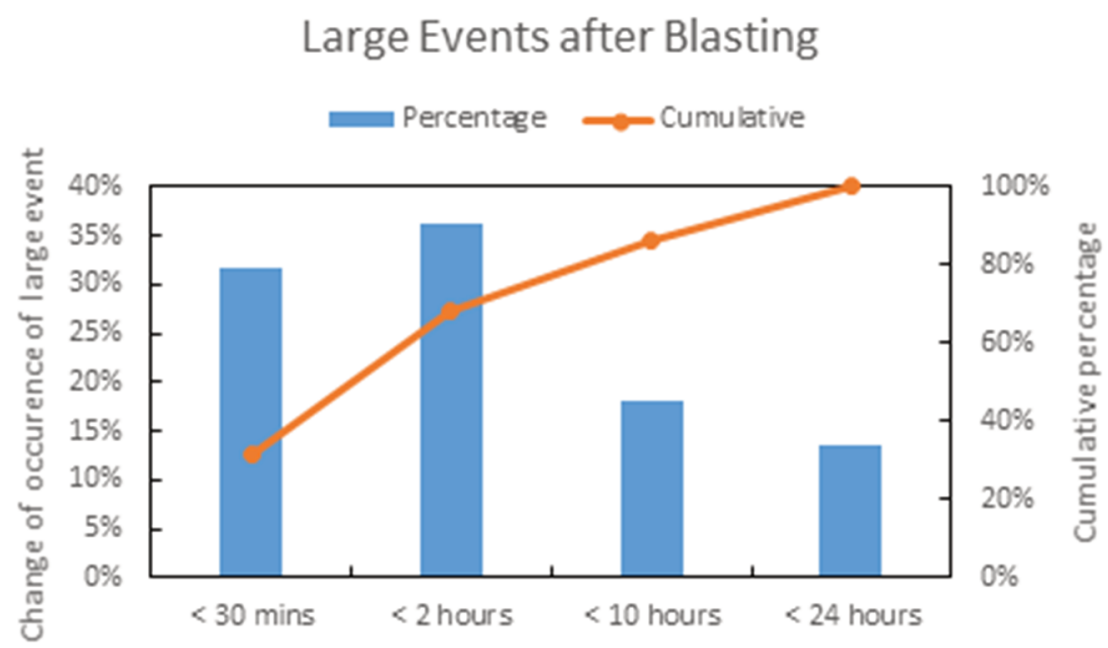

Figure 12 Time distribution of the triggered large events after blasting

\section{$6 \quad$ Aftershock series}

The temporal and spatial distribution of the aftershock sequence of the large seismic events are important because they can define the duration of the restriction period and volume of the restricted zone after a large event with increased seismic hazard and risk. The expectation is that the duration and extent of the aftershock sequences would be related to the magnitude of the seismic event. The distributions within a sphere with radius $250 \mathrm{~m}$ were analysed. The mXrap app Short-Term Response Analysis (Tierney 2018) was used for this aim, which allows one to calculate parameters of the Modified Omori Law (Utsu et al. 1995).

\subsection{Aftershocks of very large events}

Only two of the very large events had intense an aftershock series: 20 August 2012, and 19 April 2014. The response events versus distance and cumulative events after large events are shown in Figure 13. Most of the events were in Block 700-880.

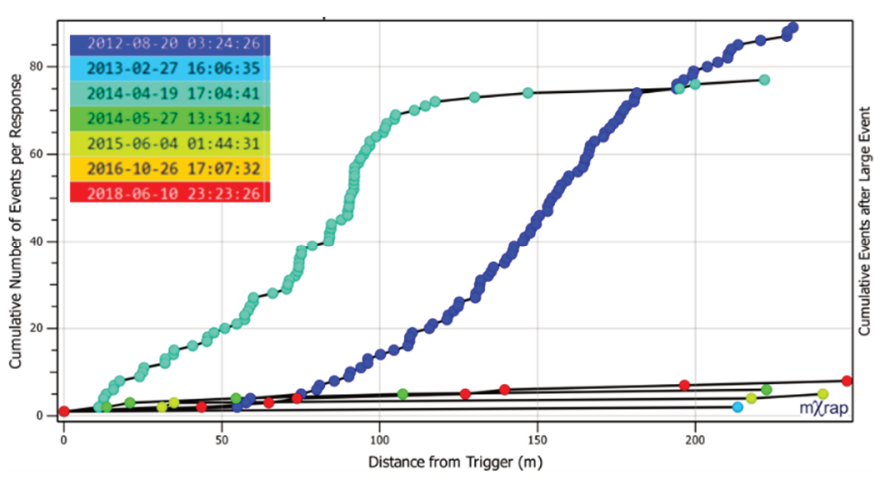

(a)

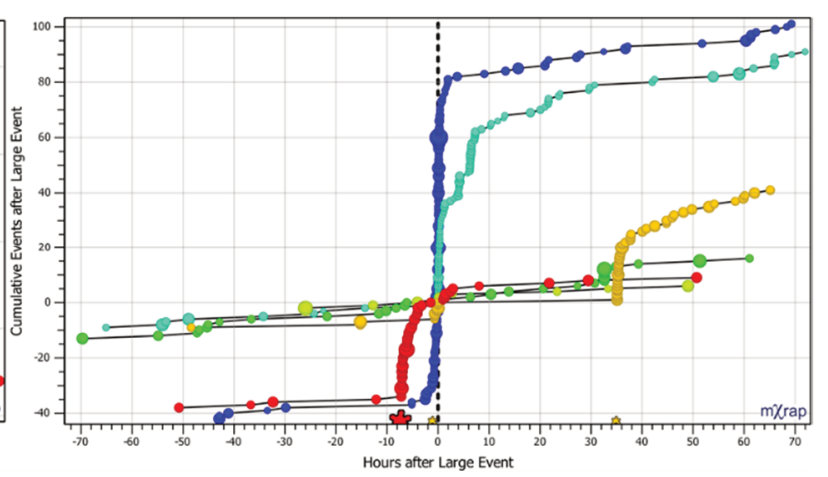

(b)

Figure 13 Aftershock of the large seismic events $(M>1)$. (a) Cumulative number of events with the distance from the main shock; (b) Cumulative number of events with time (before and after the main shock)

The most intense aftershock series belongs to the event on 20 August $2012(M=1.1)$. It also contains another very large event $(M=1.5)$. The time difference between the events is less than $10 \mathrm{~min}$, and the distance is $55 \mathrm{~m}$. Hence the spatial extent of the aftershocks cannot be considered in a standard way. The spatial extent of two individual aftershocks was $150 \mathrm{~m}$, but if two aftershock sequences combine, the spatial extent 
becomes $200 \mathrm{~m}$. In total, 90 aftershocks were recorded the first day after the first very large events. Relation to a blast was not confirmed for any of them.

The second event with an intense aftershock series was on 19 April 2014 ( $M=1.7)$. In this case, the series lasted in the order of 30-40 hours and the spatial extent was in the order of $120 \mathrm{~m}$.

The aftershock series was more complicated when the main shock was triggered by a blast as the post-blast seismicity cannot be separated from the aftershock sequence, especially if the blast and the main shock are close in time and space. There were five events that were blast-related. Each post-blast/aftershock series had a different pattern. The list below gives more details about the blast relation and the duration of the sequences.

- 27 February 2013 ( $M=1.1)$ : Triggered by blasting in Block 1100 without an aftershock.

- 19 April 2014 ( $M=1.7)$ : The first event after the blast is the main shock, and the aftershock series continued for 14 hours.

- 4 June $2015(\mathrm{M}=1.0)$ : The closest blast was nine hours before. No significant aftershock/post-blast sequence.

- 26 October 2016 ( $M=1.3)$ : The main shock occurred one hour after the blast. This blast had six post-blast events before the very large event but there were no aftershocks.

- 10 June 2018 ( $M=1.5)$ : The main shock was the fifth event in the post-blast sequence. This post-blast sequence also had two more large seismic events. The overall duration was 13 hours.

\subsection{Aftershocks of large events}

The determination of the aftershocks of the large seismic events is complicated compared to that of the very large ones, because they could be a member of the post-blast sequence, which might have another large event. Beyond that, just five large events were found having a kind of aftershock (more than five events) as seen in Figure 14.

Figure 14a shows the response events versus distance, and Figure 14b the cumulative events for the large magnitude events with their aftershocks with $250 \mathrm{~m}$ and 25 hours. None of the aftershocks had a spatial distance of more than $150 \mathrm{~m}$. The spheres with turquoise colour around $200 \mathrm{~m}$ in Figure 14a and between $-10-0$ hours in Figure $14 b$ belong to another sequence (19 April 2014).

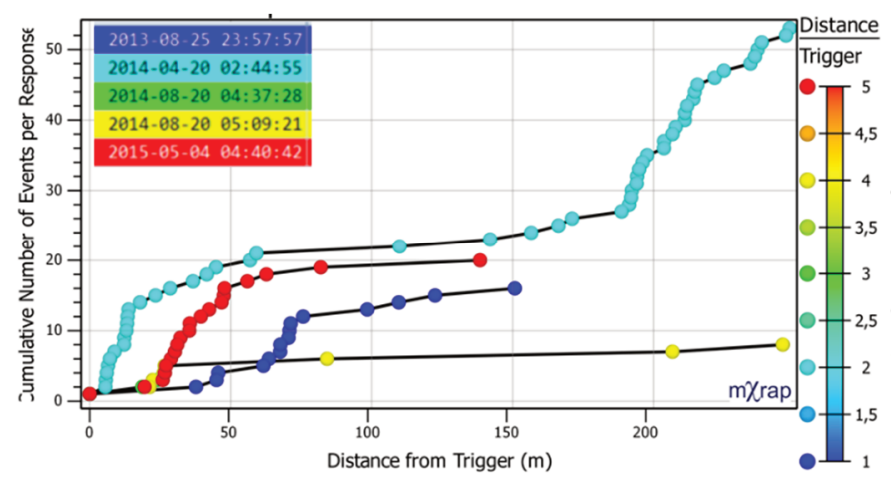

(a)

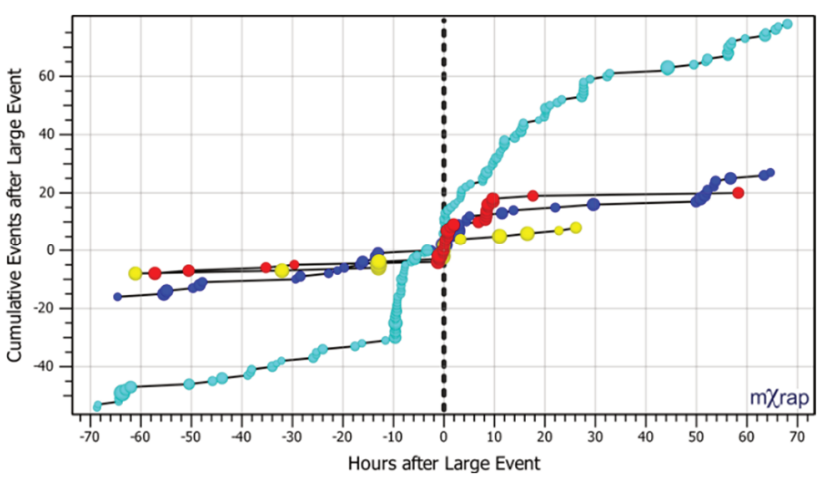

(b)

Figure 14 The aftershock of the non-blast-related large seismic events $(0<M<1)$. (a) Distance of the small magnitude events; (b) Temporal distribution of aftershocks

The individual study stated that 15 out of 83 large magnitude events $(0<M<1)$ belong to a post-blast sequence, but only 11 of them could be presented in Figure 15, due to lack of blast location in the Short-Term Response Analysis app. Two blasts generated very intense post-blast sequences (16 October 2013 and 25 March 2014). Generally, the post-blast sequences have a duration of more than 10 hours (Figure 15b) but 
their spatial extent is less than $150 \mathrm{~m}$ (Figure 15a). The detailed investigation is continuing on the post-blast sequence, but the situation after 16 October 2013 is explained in the next section.

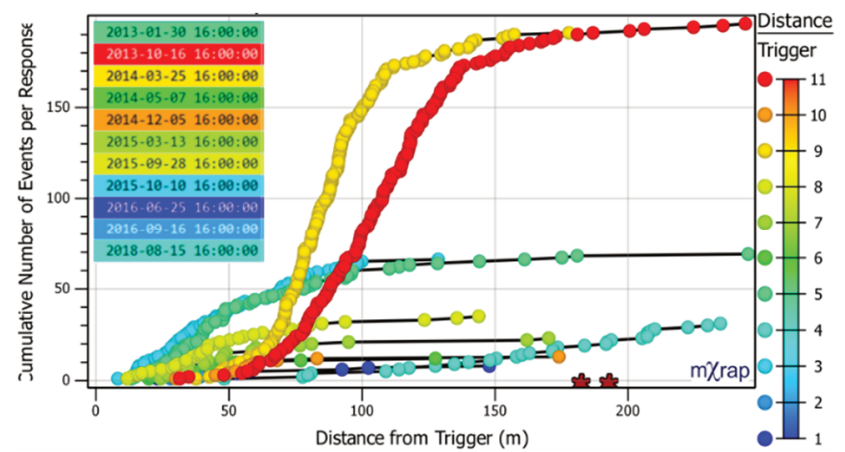

(a)

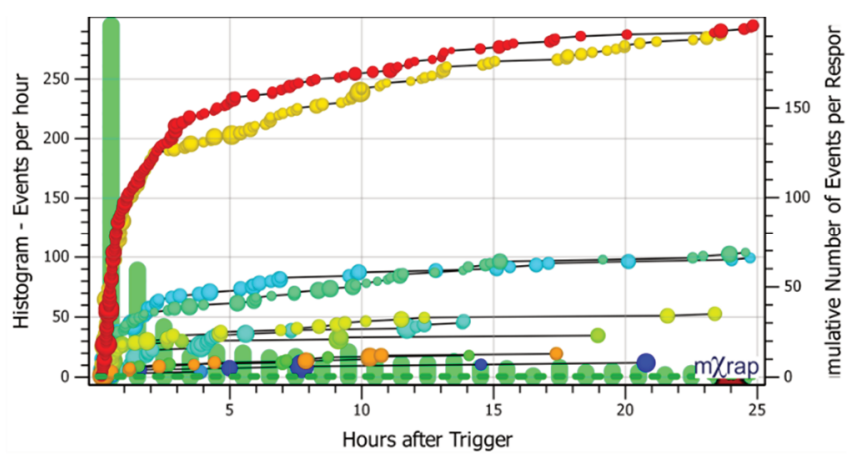

(b)

Figure 15 Aftershock/post-blast combination of the blast-related large seismic events $(0<M<1)$. (a) Distance of the small magnitude events; (b) Temporal distribution of aftershocks

\section{Damage caused by large events}

Some of the reported damages in the Lappberget orebody are related to large events and their aftershock sequences. Some details are given for two cases as examples.

One of the cases of minor damage occurred after the blast on 19 April 2014. A stope at the edge of the northeast side of the orebody was blasted. A seismic event of M 1.7 occurred one hour later followed by an aftershock series with 65 events in the first 14 hours.

There is seismic activity at a depth of approximately $-900 \mathrm{~m}$ that needs special attention. Three large magnitude events followed a blast on 16 October 2013. Damage in the rock mass was observed afterwards in Block 1100 . The three events ( $M=0.5,0.2$, and 0.2 ) occurred approximately 30 minutes after blasting on the same day. This is one of the complicated aftershock/post-blast sequence combinations. In total, 235 post-blast events/aftershocks were recorded with a duration of 62 hours. According to the mine personnel, the seismicity around the regions continued for months, so they left the area untouched for a while.

\section{Conclusion}

Garpenberg Mine, a sublevel stoping mine, is an underground seismically active mine in Sweden. It consists of a few orebodies with the Lappberget orebody being one of the biggest. Mining operations in this orebody are conducted in parallel in five different blocks separated along the depth. The geology around the orebody is highly complex, which likely influences the occurrence of seismic events. More than 11,000 seismic events were recorded from 2012 to 2018 . Only $1 \%$ of them have magnitude $M>0$. The largest event recorded in the mine by 2020 is of M 2.3. Taking into account the magnitude range of the seismic events and the possibility that they would cause damage in the rock mass, the events with $M>0$ were defined as large events and those with $M>1$ - very large events.

This study aimed at understanding: (i) spatiotemporal distribution of large seismic events; (ii) the spatial patterns of dynamic source parameters (magnitude, seismic moment, apparent stress, etc) and the type of source mechanism defined by the $E_{s} / E_{p}$ ratio; (iii) possible triggering of the large events by the production blasting; and (iv) patterns in the aftershock series. The final goal was to obtain information needed to define some rules for closing and re-opening of mine areas due to the increased seismic hazard and risk after large events and after blasting. The rules include a definition of the mine volume that needs to be closed and the duration of the closure. Data from Blocks 700, 880, and 1100 for the period 2012-2018 was used in the study.

The main characteristics of seismicity, and more specifically the large seismic events, can be summarised as follows: 
1. The seismicity in the Lappberget orebody is concentrated mostly in the northeast side (called the seismically active zone) with almost $85 \%$ of the seismic events occurring there and $90 \%$ of the large events. The larger rate of seismicity in the northeast is attributed to the more competent rock mass conditions.

2. The average frequency of the large seismic events $(M>0)$ in the Lappberget orebody is 0.8 events/month.

3. Larger seismic events in Block 700 and 880 have a specific spatiotemporal migration pattern with the earlier event in the hanging wall in the northeast side and later ones migrating down towards the footwall.

4. All large seismic events occurred around and slightly further away from the orebody. This spatial distribution can be attributed to the stress accumulation due to the mining operations.

5. The number of the seismic events in Block 1100 is the highest, but these are smaller events. The large events occurred at depth above $1,000 \mathrm{~m}$, and the so-called very large seismic events above $-750 \mathrm{~m}$. The large and very large events in the upper levels, above $700 \mathrm{~m}$, are characterised by comparatively lower apparent stress and the events below.

6. A lot of large seismic events (both non-shear and shear) occurred in the sill pillar between Blocks 880 and 1100 . They usually have very high apparent stress, which could be related to the high stress conditions in this area.

$24 \%$ of the large seismic events were triggered by blasting within $150 \mathrm{~m}$. $68 \%$ of them occurred within two hours. Another 18\% occurred between two and 10 hours after the blast, and $13 \%$ between 10 and 24 hours. No triggered events more than 24 hours after blasting were found. There is no clear spatial differentiation between the blast-related and non-blast-related events.

The aftershock series of the large seismic events in the Lappberget orebody is not common. Around $40 \%$ of the events were single events with no relation to blasting and no aftershocks. Only a few events have an intense aftershock series, and in some cases they overlapped with the post-blast seismicity. The aftershock series lasts for around 10 hours and is within $150 \mathrm{~m}$ from the main shock. In the case of more complicated situations with blast relation and multiple large events, the aftershock series lasted more than 60 hours.

Large seismic events potentially can cause damage, and it is important to understand where they occur and what their characteristics are. Understanding their dynamic source parameters is also important as some of the parameters (e.g. the apparent stress) could be used as a local stress proxy.

There are still some questions that need more work to answer. For example, there is no certain explanation for the occurrence of the non-blast-related seismic events. They could be part of the background seismicity. A possible explanation could be found by a detailed numerical model study using a 3D geological model and detailed information about the mining sequence. The migration pattern of the large seismic event in Blocks 700 and 880 possibly could be explained by this analysis too. The other questions is, what would be a possible explanation for the majority of the large events to occur in 1-2 hours after blasting even if there was no blast within $250 \mathrm{~m}$ within two days? Maybe more distant blast triggering mechanisms can be considered.

Based on the observations made here, some simple rules can be defined for closing mine areas after large seismic events (so-called re-entry protocol for large seismic events). A reasonable restriction after the large seismic event would be three hours with a $150 \mathrm{~m}$ radius from the hypocentre of the large seismic event. The duration might be extended depending on the pattern of the aftershock sequence, especially for the large seismic events that occurred after blasting. In this case, the procedure of re-entry protocol for post-blast sequences must be followed. The information obtained about the relation between the large events and blasting can be used for the re-entry protocol after blasting. 


\section{Acknowledgement}

All plots except in Figures 1, 2 and 12 are made with the mXrap software (Harris \& Wesseloo 2015). We express our appreciation to the people from the Australian Centre for Geomechanics for their help and customisation of the $m X$ rap software. This study is financially supported by the strategic innovation program SIP STRIM (project No 2016-02629), a joint venture by Vinnova, Formas and the Energy Agency (Sweden), and Boliden.

\section{References}

Ahmadi, O, Juhlin, C, Malehmir, A \& Munck, M 2013, 'Case history high-resolution 2D seismic imaging and forward modeling of a polymetallic sulfide deposit at Garpenberg, central Sweden', Geophysics, vol. 78 no. 6, pp. B339-350.

Allen, R, Bull S, Ripa M \& Jonsson, R 2003, 'Regional stratigraphy, basin evolution, and the setting of stratabound $\mathrm{Zn}-\mathrm{Pb}-\mathrm{Cu}-\mathrm{Ag}-\mathrm{Au}$ deposits in Bergslagen, Sweden', Project 03-1203/99, Geological Survey of Sweden and Boliden Mineral AB.

Brune, JN 1970, 'Tectonic stress and the spectra of seismic shear waves from earthquakes', Journal of Geophysical Research, vol. 75, no. 26, pp. 4997-5009.

Disley, N 2014, 'Seismic risk and hazard management at Kidd Mine', in M Hudyma \&Y Potvin (eds), Proceedings of the Seventh International Conference on Deep and High Stress Mining, Sudbury, pp. 107-121.

Eneva, M 1998, 'In search for a relationship between induced microseismicity and larger events in mines', Tectonophysics, vol. 289, iss. 1-3, pp. 91-104.

Erguncu Güçlü, i 2016, Rockmass Reaction to Blasting in Mines Studied by Local Induced Seismicity, master thesis, İstanbul Technical University, İstanbul, https://polen.itu.edu.tr/handle/11527/15842

Friedel, MJ, Scott, DF \& Williams, TJ 1997, 'Temporal imaging of mine-induced stress change using seismic tomography', Engineering Geology, vol. 46, no. 2, pp. 131-41.

Harris, PC \& Wesseloo, J 2015, mXrap, version 5, computer software, The Australian Centre for Geomechanics, The University of Western Australia, Perth, http://www.mXrap.com

Hudyma, M \& Potvin, YH 2010, 'An engineering approach to seismic risk management in hardrock mines', Rock Mechanics and Rock Engineering, vol. 43, pp. 891-906.

Jansson, N 2011, The Origin of Iron Ores in Bergslagen, Sweden, and Their Relationships with Polymetallic Sulphide Ores, PhD thesis, Luleå University of Technology, Luleå.

Jansson, NF \& Allen, RL 2011, 'Timing of volcanism, hydrothermal alteration and ore formation at Garpenberg, Bergslagen, Sweden', GFF, vol. 133, no. 1-2, pp. 3-18.

Mendecki, AJ 1997, 'Spectral analysis and seismic source parameters', in AJ Mendecki (ed.), Seismic Monitoring in Mines, Springer, Dordrecht, https://doi.org/10.1007/978-94-009-1539-8_8

Morkel, IG, Wesseloo, J \& Potvin, Y 2019, 'The validity of Es/Ep as a source parameter in mining seismology', in W Joughin (ed.), Proceedings of the Ninth International Conference on Deep and High Stress Mining, The Southern Africa Institute of Mining and Metallurgy, Johannesburg, pp. 385-398.

Nordström, E, Dineva, S \& Nordlund, E 2017, 'Source parameters of seismic events potentially associated with damage in Block $33 / 34$ of the Kiirunavaara Mine (Sweden)', Acta Geophysica, vol. 65, no. 6, pp. 1229-1242.

Riemer, KL \& Durrheim, RJ 2012, 'Mining seismicity in the Witwatersrand Basin: monitoring, mechanisms and mitigation strategies in perspective', Journal of Rock Mechanics and Geotechnical Engineering, vol. 4, no. 3, pp. 228-249, http://dx.doi.org/ 10.3724/SP.J.1235.2012.00228

Tierney, S 2018, mXrap software app: Mining Induced Seismicity - Event Density Isosurfaces, version 1, The Australian Centre for Geomechanics, The University of Western Australia, Perth, http://www.mXrap.com

Utsu, T, Ogata, Y \& Matsu'ura, RS 1995, 'The centenary of the Omori formula for a decay law of aftershock activity', Journal of Physics of the Earth, vol. 43, pp. 1-33.

Villaescusa, E 2014, Geotechnical Design for Sublevel Open Stoping, CRC Press, Boca Raton. 